\section{Afghanistan Digital Library Initiative: Revitalizing an Integrated Library System}

\section{Yan Han and Atifa Rawan}

This paper describes an Afghanistan digital library initiative of building an integrated library system (ILS) for Afghanistan universities and colleges based on open-source software. As one of the goals of the Afghan eQuality Digital Libraries Alliance, the authors applied systems analysis approach, evaluated different open-source ILSs, and customized the selected software to accommodate users' needs. Improvements include Arabic and Persian language support, user interface changes, call number label printing, and ISBN-13 support. To our knowledge, this ILS is the first at a large academic library running on open-source software.

The last quarter-century has been devastating for Afghanistan, with an uninterrupted period of invasions, civil wars, and oppressive regimes. "Since 1979, the education system was virtually destroyed on all levels. Schools and colleges were closed, looted, or physically reduced; student bodies and faculties were emptied by war, migration, and economic hardship; and libraries were gutted."1 Kabul University (KU), for example, was largely demolished by 1994 and completely closed down in 1998. It is universally recognized that Afghanistan desperately needs trained faculty, teachers, librarians, and staff. The current state of the higher education system is one of dramatic destruction and deterioration. Based on Rawan's assessments of KU Library, most of its collections were damaged or destroyed. She found that there were approximately 60,000 to 70,000 books in English, 2,000 to 3,000 books in Persian, and 2,000 theses in Persian. None of these collections have manual or online catalog records. The library has eighteen staff members, but not all are fully trained in library activities. ${ }^{2}$ Rebuilding the educational infrastructure in Afghanistan is essential.

\section{Afghan equality digital libraries alliance}

The University of Arizona (UA) Library has been involved in rebuilding academic libraries in Afghanistan since April 2002. In 2005, we were invited to be part of the Digital Libraries Alliance (DLA) as part of the Afghan eQuality Alliances: 21st Century Universities for Afghanistan initiative funded by the USAID and Washington State University. DLA's goal is to build the capacity of Afghan libraries and librarians to work with open source digital libraries platforms; and to provide and enhance access to scholarly information resources and open content that all Afghanistan universities can share.

\section{Revitalizing the Afghan ILS}

An integrated library system (ILS) usually includes several critical components, such as acquisitions, cataloging, catalog (search and find), circulation, and patron management. Traditionally it has been the center of any library. Recent developments in digital libraries have resulted in distributed systems in libraries, and the ILS is treated as one of many digital library systems. It still is critical to have a centralized ILS to provide a primary way to access library-owned materials for Afghanistan universities and colleges. Other services, such as interlibrary loan and other digital library systems, can be further developed to extend libraries' services to users and communities.

The UA library is working collaboratively with other DLA members, including universities around the world and universities in Afghanistan. One of the goals is to develop a digital library environment, including a centralized ILS for four academic universities in Kabul (Kabul University, Polytechnic University, Kabul Medical University, and Kabul Education University). In the future, the ILS will include other regional institutions throughout Afghanistan. The ILS will support 30,000 students and 2,000 faculty in Afghan universities and colleges.

\section{Overview of the ILS market}

Currently the ILS market is primarily dominated by commercial systems, such as Innovative Interface, Endeavor, and Sirsi. Compared with other computing areas, open-source systems in ILS are immature and limited, as there are only a few products available, and most of them do not have the full features of an ILS. However, they are providing a valuable alternative to those costly commercial systems.

Based on the availability of existing funding, experiences with commercial vendors, and consideration of vendor supports and future directions, the authors decided to build a digital library infrastructure with the open concept (open access, open source, and open standards). The decision is widely influenced by globalization, open access, open source, open standards, and increasing user expectations. At the same time, the decision gives us an opportunity to develop and integrate new tools and services for libraries as suggested by the University of California. ${ }^{3}$

Koha is probably the most renowned open-source ILS. It is

Yan Han (hany@u.library.arizona.edu) is Systems Librarian and Atifa Rawan (rawana@u.library.arizona.edu) is Librarian at the University of Arizona Libraries, Tucson. 
a full-featured ILS, developed in New Zealand and first deployed in Horowhenua Library Trust in 2000. So far Koha has been running in a few public and special libraries. The underlying architecture is the Linux, Apache, MySQL, and Perl (LAMP) stack. Building on a similar LAMP (Linux, Apache, MySQL, and PHP) architecture, OpenBiblio has a relatively short history, releasing its first beta 0.1 .0 version in 2002 and currently in beta 0.5.1 version. WEBILS is an open-source ILS based on UNESCO's CDS/ISIS database, developed by the Institute for Computer and Information Engineering in Poland. The software has some ILS features, including cataloging, catalog (search and find), loan, and report modules. WEBLIS must run on Windows and Windowbased Web servers, such as Xitami/ Microsoft IIS and ISIS database. GNUTECA, another open-source ILS widely deployed in South America universities, was developed in Brazil. As with WEBILS, it has some ILS features, such as cataloging, cata$\log$, and loan; however, the software interface is written in Portuguese, which presents a language barrier for U.S. and Afghanistan users. The paper Open Source Integrated Library Systems provides a good overview of other systems. $^{4}$

\section{Systems Analysis}

The authors adopted systems analysis by taking account of Afghan collections, users' needs, and systems functionality required to perform essential library operations. Koha was chosen as the base software, due to its functionality, maturity, and support. Some of the reasons are:

- The software architecture is opensource LAMP, which is popular, stable, and predominant.

- Our staff have skills in these open software systems.

- It is a full-featured open-source
ILS. Certain components, such as multiple branch support and user management, are critical.

- Two large public libraries serving population of 30,000 users in New Zealand and United States have been running their ILS on Koha for a few years. The software is stable, and most bugs have been fixed.

- Koha has a mailing list that is used by Koha developers and users as a communication tool to ask and answer questions.

Kabul Universities have computer science faculty and students who have the capacity to participate in the development. Due to working schedules and locations, we prefer to develop and maintain the system in the UA Library. The technical project team consists of three people: Yan Han, who is responsible for managing the overall implementation and development in the open source ILS system; one part-time (twenty hours per week) student developer whose major task is to develop and manage source code; and a temporary student (ten hours per week for two months) responsible for translating English to Farsi and Dari. Testing tasks, such as unit testing and system testing, are shared by all members of the team.

\section{Major challenges}

\section{Farsi and Dari languages support}

Koha version 2.2 cannot correctly handle East Asian language records, including Farsi and Dari records. Supporting Persian, Farsi, and Dari records is a very important requirement, as these Afghan Universities have quite a few Persian and Dari materials. Koha generates a Webbased graphical user interface (GUI) through Perl included templates that use a HTML meta tag with Western character set (ISO-8559-1) to encode characters. Browsers such as Internet Explorer and Firefox use the meta tag to decode characters with a predefined character set. Therefore, other characters, such as Arabic and Persian as well as Chinese would not be displayed correctly. The Perl templates were identified and modified to allow characters to be encoded in Unicode, and this solved the problem. Persian and Dari characters can be entered into the cataloging module and displayed correctly in the GUI. However, we should understand the limitations of this approach when dealing with other East Asian character sets, such as Chinese characters. Only frequently used characters can be represented. A project of Academia Sinica is one of the efforts to deal with 65,000 unique Chinese characters. ${ }^{5}$

\section{Farsi/Dari GUI}

As the project is designed for local Afghanistan users, there is a need for a Farsi and Dari GUI. The current version of Koha does not have such an interface, and we decided to create a new Farsi/Dari GUI for the OPAC. The Koha system's internal structure is logically arranged; therefore, our development work in translation is not difficult to manage. The translation student translates English words in Perl template files into Farsi and Dari. At the same time he works with the developer to make sure it is displayed correctly in the OPAC. Figure 1 is the screenshot of the GUI.

\section{Other improvements}

We further developed a spine label printing module and integrated the module into the ILS, as there is no such function provided. The module allows library staff to print one or more standardized labels (1.5 inches high by 1 inch wide) with OCLC formats on Gaylord LSL 01 paper, which has fifty-six labels per sheet. 


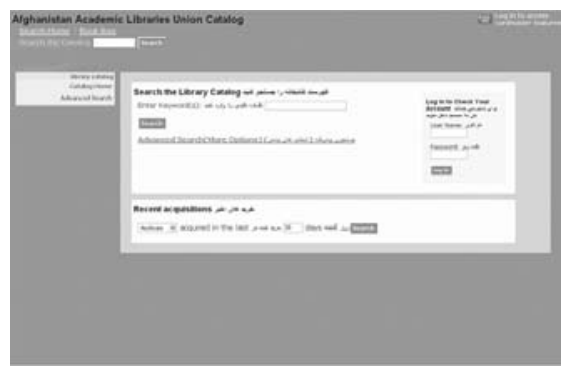

Figure 1: Afghanistan academic libraries union catalog in Farsi/Dari

Lstaff can select an appropriate label slot to start and print out his or her choices of labels through the Web preview feature. This feature eases library staff operations and provides cost savings for label papers.

ISBN-13 replaced ISBN-10 after January 1, 2007, and any ILS has to be able to handle the new ISBN-13. Our ILS has been improved to handle both ISBN standards. Thanks to Koha's delegation of the GUI and major functionality, interfaces such as fonts and Web pages can be modified through the templates and CSS. A Z39.50 service has been configured to allow users to search other libraries' catalogs.

\section{Hardware and software support}

Afghanistan is still developing its fundamental infrastructure: electricity, transportation, and communication. When considering buying hardware for the ILS, difficult issues, such as server services and computer parts, have to be solved. Even international IT companies, such as Dell, HP, and
IBM, have very limited services and support in Afghanistan.

Regarding software and system support, our strategies are to:

- maintain and develop the open source software at the UA library by the project team;

- run one server in Kabul, Afghanistan, administrated by a local system administrator.

- run one server in the UA library administrated by the library's system administrator.

\section{Cost}

We estimated our overall cost for building the open-source system is low and reasonable.

The system is currently running on a Dell 2800 server $(\$ 5,000$ for $3 \mathrm{GHZ}$ CPU, 4GB RAM, and five 73GB hard drives), kernel built Debian Linux (free), Apache 2 (free), MySQL (free), and Perl (free). Han spends four hours per week for coordination, communication, and management of the project. The student developer works twenty hours per week for development and maintenance, while the translation student will spend one hundred hours for translation.

\section{Conclusion}

Revitalizing an Afghan ILS is the first important goal to build digital library initiatives for the Afghanistan higher education system. By understanding Afghan university libraries, collections, and users, the UA library is working with other DLA members to build the open source ILS. The new Farsi and Dari user interface, language support, and other improvements have been made to meet needs of Afghan universities and colleges. The cost of using and developing existing open source software is reasonable.

\section{Acknowledgments}

We thank USAID, Washington State University, and other DLA members for providing support. This work was supported by USAID and Washington State University.

\section{References and notes}

1. Nazif Sharani et. al., Conference transcription, Conference on Strategic Planning of Higher Education for Afghanistan, 2002, Indiana University, Bloomington, Oct. 6-7.

2. Atifa Rawan, Transformation in Afghanistan: Rebuilding Libraries, paper presented at AZLA conference, Mesa, Ariz., Oct. 11-13, 2005.

3. The University of California Libraries, Rethinking How We Provide Bibliographic Services for the University of California, 2005, http://libraries.universityofcalifornia.edu/sopag/BSTF/Final. pdf.

4. Eric Anctil and Jamshid Beheshti, Open Source Integrated Library Systems: An Overview, 2004, www.anctil.org/users/ eric/oss4ils.html (accessed Nov. 5, 2006).

5. Derming Juang et al., "Resolving the Unencoded Character Problem for Chinese Digital Libraries," Proceedings of the 5th ACM/IEEE-CS Joint Conference on Digital Libraries, JCDL 2005, Denver (June 7-11, 2005): 311-19 (New York: ACM Pr., 2005).

\section{Index to Advertisers}

LITA cover 2, cover 3 , cover 4 